\title{
Antagonism between salicylate and the CAMP signal controls yeast cell survival and growth recovery from quiescence
}

\author{
Maurizio D. Baroni ${ }^{1, *}$, Sonia Colombo ${ }^{2}$ and Enzo Martegani ${ }^{2, *}$ \\ ${ }^{1}$ Dipartimento di Biologia, Università di Padova, 35133 Padova, Italy. \\ 2 Dipartimento di Biotecnologie e Bioscienze, Università Milano Bicocca, 20126 Milano, Italy. \\ * Corresponding Authors: \\ Maurizio David Baroni, University of Padua, Department of Biology, Via Ugo Bassi 58/b, 35131 Padova, Italy; \\ E-mail: mauriziodavide.baroni@unipd.it \\ Enzo Martegani, University of Milano-Bicocca, Department of Biotechnology and Bioscience, Buildings U3-U4, Piazza della Scienza 2- \\ 4, 20126 Milano, Italy; E-mail: enzo.martegani@unimib.it
}

ABSTRACT Aspirin and its main metabolite salicylate are promising molecules in preventing cancer and metabolic diseases. $S$. cerevisiae cells have been used to study some of their effects: (i) salicylate induces the reversible inhibition of both glucose transport and the biosyntheses of glucose-derived sugar phosphates, (ii) Aspirin/salicylate causes apoptosis associated with superoxide radical accumulation or early cell necrosis in MnSOD-deficient cells growing in ethanol or in glucose, respectively. So, treatment with (acetyl)-salicylic acid can alter the yeast metabolism and is associated with cell death. We describe here the dramatic effects of salicylate on cellular control of the exit from a quiescence state. The growth recovery of long-term stationary phase cells was strongly inhibited in the presence of salicylate, to a degree proportional to the drug concentration. At high salicylate concentration, growth reactivation was completely repressed and associated with a dramatic loss of cell viability. Strikingly, both of these phenotypes were fully suppressed by increasing the cAMP signal without any variation of the exponential growth rate. Upon nutrient exhaustion, salicylate induced a premature lethal cell cycle arrest in the budded-G2/M phase that cannot be suppressed by PKA activation. We discuss how the dramatic antagonism between cAMP and salicylate could be conserved and impinge common targets in yeast and humans. Targeting quiescence of cancer cells with stem-like properties and their growth recovery from dormancy are major challenges in cancer therapy. If mechanisms underlying CAMP-salicylate antagonism will be defined in our model, this might have significant therapeutic implications. doi: $10.15698 /$ mic2018.07.640

Received originally: 25.08.2017;

in revised form: 31.01 .2018 ,

Accepted 14.03.2018,

Published 26.03.2018.

Keywords: Salicylate, cyclic AMP, cellular growth, cell death, yeast, NSAIDS.
Abbreviations:
CAMP - cyclic AMP,
$D T$-Doubling Time,
$P C D$ - programmed cell death,
PKA - cAMP dependent protein
kinase $A$,
$S A$ - salicylic acid,
$w t$ - wild type.

\section{INTRODUCTION}

The nonsteroidal anti-inflammatory drugs (NSAIDs) can act through multiple mechanisms, some of which are also driven by their metabolites. This is the case of Aspirin (acetylsalicylic acid), one of the most used internationally drugs due to its anti-inflammatory, anti-thrombotic, anti-pyretic and analgesic properties [1], and its main metabolite salicylate (2-hydroxybenzoic or salicylic acid, SA). Natural salicylates are among the oldest drugs used by humans since they are ubiquitous in plants (where they exert important functions) [2] and particularly abundant in some species (e.g. in the willow Salix alba, where they were originally extracted from its bark) [3].

Aspirin is a synthetic mono-acetylated SA derivative that can transfer in vivo its acetyl group to eight different amino acids of hundreds of proteins involved in key biological and cellular functions with widespread but, in most cases, still largely unknown consequences ([4] and studies discussed therein). In this context, the acetylation of cyclooxygenases (COX1 and 2) contributes to varying degrees 
and with different mechanisms to the Aspirin multiple effects $[1,5]$.

Aspirin has a very short half-life in the body $(\sim 15-20$ minutes) due to its rapid hydrolysis [6], both spontaneous and via enzyme-catalyzed in vivo hydrolysis. In particular, it is rapidly broken down to salicylate by both serum and cellular esterases so that only a small fraction can reach the peripheral tissues [7]. In addition, unlike platelets the nucleated cells are able to resynthesize or deacetylate its acetylated targets. As a consequence, Aspirin must also be considered a pro-drug, which is quickly transformed into its main active metabolite salicylate [3]. This latter is much more stable having a half-life ranging between 3-5 hours (in most cases) but half-lives of 30-40 hours has been recorded (its dosage and physiopathological factors markedly influencing the pathways and rate of metabolism) [8]. The peak serum concentrations of SA, following oral Aspirin administration in both laboratory animals and humans, are also much higher than those of Aspirin [8, 9]. Finally, salicylic acid is obtained from dietary intake, with higher levels of SA in vegetarians overlapping with levels in patients on low-dose Aspirin regimens [10].

Daily low-dose Aspirin taken for cardioprevention has been also causally linked to a decreased incidence of both gastrointestinal carcinomas and (less strongly) some other cancers. There are plausible COX-dependent as well as many COX-independent multiple mechanisms underlying the cancer preventive efficacy of Aspirin/SA. These involve several Aspirin/SA molecular targets that appear to act by decreasing inflammation, platelet activation, glucose metabolism, mitochondrial oxidative phosphorylation, protein translation and cell proliferation as well as by enhancing apoptosis, differentiation, stress responses, tumour immunosurveillance and autophagy (summarized and discussed in [11]). Most of these cell processes are conserved among eukaryotes.

The elucidation of the anticancer mechanisms of Aspirin/salicylate can greatly benefit from the use of experimental models, including Saccharomyces cerevisiae as shown by some previous pioneering studies in budding yeast [12]. These studies strongly indicate that at least some of the above mentioned cell processes are similarly regulated by Aspirin/SA in S. cerevisiae cells. Briefly, the treatment of yeast cells with Aspirin and/or salicylic acid can reversibly repress the yeast glucose transport and metabolism and it is associated with programmed cell death (PCD) (discussed in [12]). Previous studies have indicated SA stereospecific binding sites located within yeast cells and SA reversible inhibition of glucose transport [13] and inhibition of uptake and distribution of ${ }^{14} \mathrm{C}$ from $\left[{ }^{14} \mathrm{C}\right]$ glucose into sugar phosphates, uridine diphosphoglucose and, more markedly, trehalose 6-phosphate (T6P) and trehalose [14]. In addition, studies on the growth inhibitory and proapoptotic effects of Aspirin and the derived salicylate in S. cerevisiae indicated that yeast mitochondria constitute one of its critical targets (reviewed in [12]). Among factors which play roles in PCD induced by Aspirin/SA are ROS (reactive oxygen species) and mitochondrial dysfunc- tions with inhibition of the electron transport chain and aerobic respiration. In addition, Aspirin/SA induced apoptosis is associated with superoxide radical accumulation and $\mathrm{NAD}(\mathrm{P}) \mathrm{H}$ oxidation [15], and low doses of salicylate can confer long-term cytoprotective resistance against $\mathrm{H}_{2} \mathrm{O}_{2}$-induced oxidative stress [16]. This Aspirin/SA PCD model also includes decrease of $\Delta \Psi_{m}$, release of CytC (cytochrome c) and $\mathrm{pH}$ lowering [17] but it was limited to a condition of ethanol metabolism and MnSOD (manganese dependent superoxide dismutase)deficiency. In contrast, early cell necrosis has been observed for a glucose cultured population of yeast cells treated with Aspirin [18]. Finally, a dominant negative effect of salicylate on yeast heat-shock induced transcription linked to intracellular $\mathrm{pH}$ decrease has also been described [19]. Hence, although still limited this picture seems to be consistent to that observed in mammalian cells. Noteworthy, yeast cells have been successfully used to further deepen our knowledge on other NSAIDs, such as Diclofenac (and related drugs) [20] and Ibuprofen [21].

The present study gives a further significant contribution to the field by describing totally new phenotypes of yeast cells treated with salicylate. We show how salicylate can strongly inhibit exit from G0 phase by delaying or even blocking growth reactivation of profoundly quiescent cells. We also describe a dramatic antagonism between salicylate and CAMP (a ubiquitous signal known to regulate growth/proliferation and other vital processes [22]), which determines the ability of cells to resume growth and their own survival. We also argue that salicylate could interact not only with the CAMP pathway but with other metabolic hubs too. Preliminary data showing that salicylate also impairs cell cycle arrest in G1/GO upon nutrient exhaustion further support this view. Mechanisms allowing the interplay between salicylate and PKA may be evolutionarily conserved and their knowledge can have future therapeutic implications in prevention of cancer and metabolic diseases.

\section{RESULTS}

Salicylate has a modest and transient effect on cellular growth of log phase cells

An exponentially growing culture of wt (wild type) yeast cells (W303-1A) was treated with $3 \mathrm{mM}$ salicylate and both the cell number and the of $O D_{600}$ values were followed over time. Salicylate only induced a transient and limited inhibition of both the cell proliferation (followed as cell number increase) and biomass accumulation (monitored as OD increase) (Figure 1A). After less than two hours from its addition the culture regained a growth rate comparable to that of the untreated control one (Figure $1 \mathrm{~A}$ and Supplementary Figures S1A, C). The percent of budded or S/G2/M cells (Supplementary Figures S1A, B) and the cell volume distribution (data not shown) were also unaltered by the drug during the exponential phase of growth. 

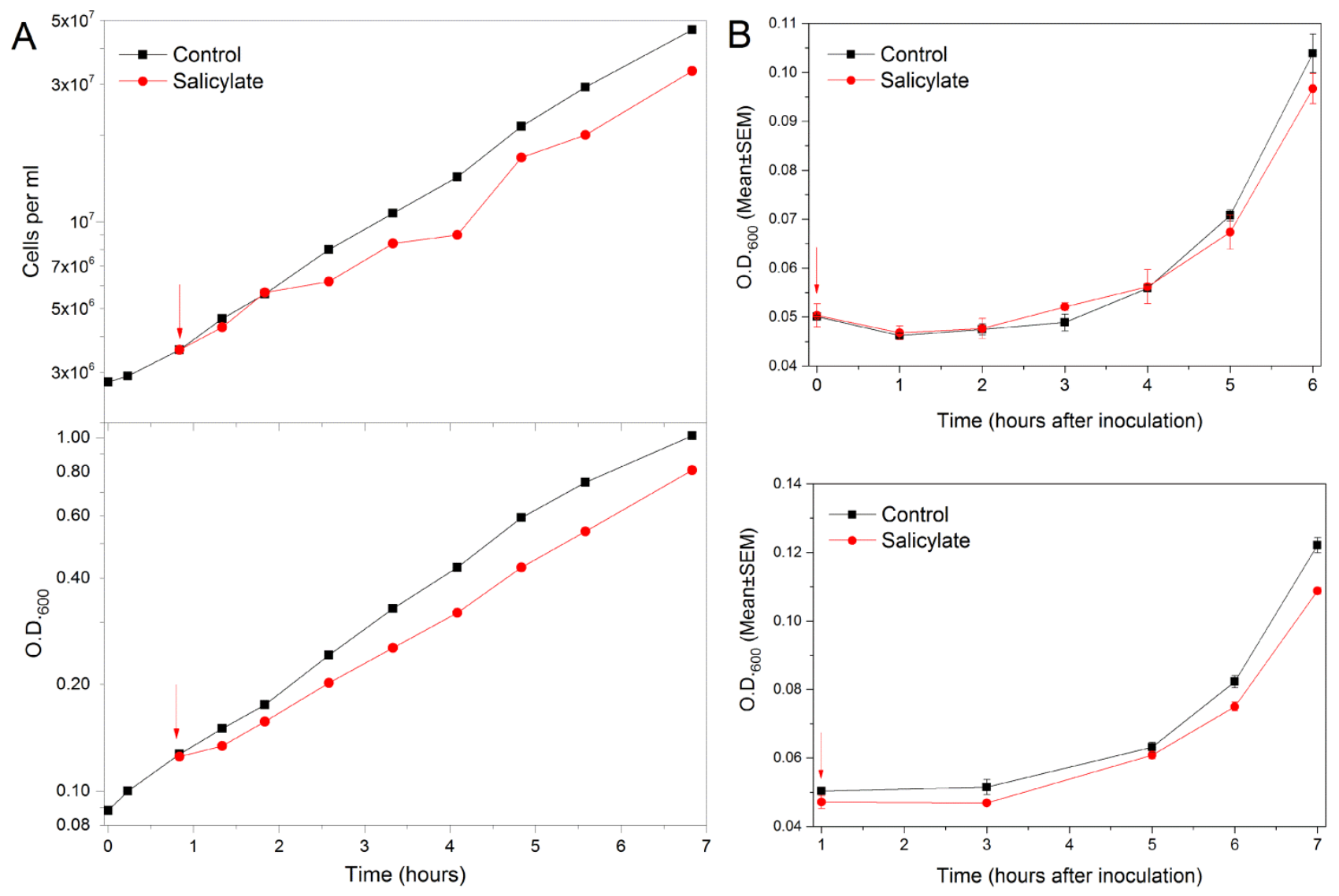

FIGURE 1: Limited salicylate effects on proliferation of active yeast populations. (A) Mild transient inhibition of yeast exponential growth with salicylate. An exponentially growing culture of wt yeast cells ( $\square$ ) was supplied (red arrow) with $3 \mathrm{mM}$ salicylate $(\bullet)$. The cell number per $\mathrm{ml}$ (upper graph) and the Optical Density (OD) at $600 \mathrm{~nm}$ (lower graph) were monitored over time. The $\log _{10}$ of each value was graphically plotted versus time. After a transient and modest growth inhibition due the drug the culture Doubling Time (DT) returned similar to that of untreated control. DTs from the cell number increases: 1.66 (control) and 1.69 (SA) hours. DTs from OD 600 values: 2.1 (control) and 2.2 (SA) hours. DTs were calculated in late log phase (last 5 points), so are expected to be longer if derived from O.D. ${ }_{600}$. (B) Unaltered lag phase before growth recovery of chronologically young yeast populations supplied with salicylate. wt yeast cells were re-inoculated into fresh medium after 2 days (upper panel) or 4 days (lower panel) spent into stationary phase. $\mathrm{OD}_{600 \mathrm{~nm}}$ values were monitored in control untreated cells ( $\square$ ) and cells supplied with $3 \mathrm{mM}$ salicylate $(\bullet)$. Values of Means ( \pm SEM) derived from three independent repeats (each performed in triplicate) were plotted against time.

\section{Salicylate impairs the G1/G0 arrest of yeast cells ap- proaching the stationary phase}

Interestingly, salicylate supplied during log-phase impaired the cell's ability to properly arrest in G1 phase upon nutrient exhaustion. Indeed, the drug caused a large fraction of cells approaching the stationary phase to prematurely arrest cell division in the budded-G2/M phase (Supplementary Figures S2B, D). Overall biomass accumulation was also inhibited as indicated by both the smaller $\mathrm{OD}_{600}$ values in the SA-treated culture and the reduction of cell volumes (Supplementary Figures S2A-E). In addition, the presence of very small budded cells in the stationary phase suggested there might be an altered cell size control (Supplementary Figures S2A, B). Virtually all starved salicylate treated cells became unviable (Supplementary Figure 2B) (the volume reduction was also partially due to cell shrinkage). All the phenotypic traits were independent of the genetic background and were scarcely influenced by better nutri- tional conditions (Supplementary Figures S2A-C). Surprisingly, at least in solid media supplemented with $3 \mathrm{mM} \mathrm{SA}$ cells were able to accumulate glycogen, though to a lesser extent than control cells (data not shown). Glycogen is a storage carbohydrate marking the $\mathrm{G} 0$-quiescent phase [22]. So, the massive loss of viability seen in liquid media might be due more specifically to a defective cell cycle arrest rather than a GO defect. Alternatively, the upper cells of the colonies might come into contact with much less SA respect to the medium concentration. Different quiescence parameters should be appropriately probed to establish the cause of cell death.

The lag phase duration after refeeding short-term stationary phase cultures is unaffected by salicylate

We then tested the ability of cells to restart growing in the presence of salicylate after a short period spent in a quiescence state. Pilot experiments suggested that after a few 
days into stationary phase the reactivation of growth was not affected by $3 \mathrm{mM}$ salicylate (data not shown). Indeed, the lag time before growth was virtually unaffected by the drug until $\sim 4$ days of dormancy (Figure 1B and Supplementary Figure S3B). In contrast, its duration was sensitive to the time the cells previously spent in $\mathrm{G} 0$, as expected (Supplementary Figures S3A, B). The growth rate during the early exponential phase was also unaltered or poorly affected by salicylate (Figures $1 \mathrm{~B}$ and S3B).

\section{Salicylate strongly inhibits the growth recovery of chrono- logically aged yeast cells}

S. cerevisiae is one of the most used models to investigate the molecular processes of aging in eukaryotes. Budding yeast cells deprived of essential nutrients undergo a process of chronological aging that induces profound metabolic changes [23]. As salicylate appears to affect sugar metabolism/sensing in both yeast and higher eukaryotes (more details in Introduction and Discussion) we repeated the test by using long-term ( $\sim 3$ weeks) stationary phase wt populations. The cell densities monitored after many hours in fresh medium containing various SA concentrations showed that the growth recovery of these aged cells can be dramatically impaired by salicylate, in proportion to the drug concentration (Figure 2A). The effect is evident even at the lowest used concentration $(250 \mu \mathrm{M}$; see also Supplementary Figures S4A, B and Bonferroni statistical analyses in Figure S4C, left panel), which is similar to blood SA concentrations reached during therapies with Aspirin (going from a minimum of $\sim 0.02-0.1 \mathrm{mM}$ to a maximum of 1-2 mM concentration) $[8,9]$. The drug effects appear to be reversible (preliminary data in Supplementary Figure S4D) in agreement with previous reports $[12,13]$.

PKA activation induces an early reactivation of growth and suppresses the delay in growth recovery induced by salicylate

In budding yeast, cyclic AMP (cAMP) is produced in response to sensing and catabolism of fermentable carbon sources (in particular glucose) and several other nutrients. CAMP indeed is a key signal for driving cells out of a quiescent state [22]. So, in principle the activation of cAMPdependent kinases (PKAs) might counteract the growth inhibition due to salicylate.

The quadruple cyr $1 \Delta p d e 2 \Delta m s n 2 \Delta m s n 4 \Delta$ mutant strain (GG104, isogenic to W303-1A), missing the essential adenylate cyclase encoding gene (CYR1 or CDC35), is unable to produce CAMP but it shows a good viability due to the inactivation of the main stress transcription factors Msn2p and Msn4p, two powerful PKA antagonists [24]. In the same mutant cells it is possible to conveniently control the level of PKA activation by simply adding different concentrations of cAMP into the culture medium (this is greatly favoured by the inactivation of the high-affinity CAMP phosphodiesterase Pde2p $[25,26])$.

We first established that cAMP signal and, perhaps more surprisingly, the activity of Msn2p and Msn4p are not needed for the salicylate induced phenotypes. Indeed, the
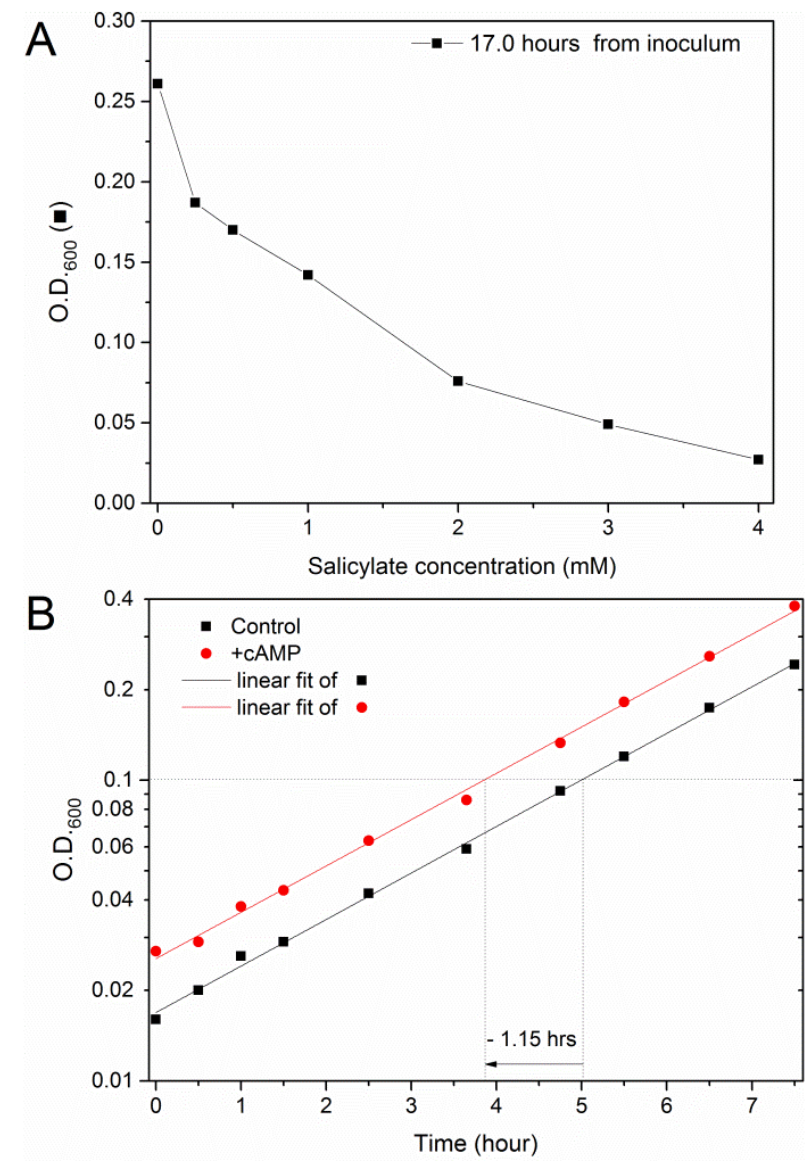

FIGURE 2: Opposite effects of salicylate and cAMP signalling pathway on yeast growth reactivation. (A) Growth reactivation delay of chronologically aged yeast cells induced by salicylate. wt cells arrested into stationary phase for 22 days were inoculated into fresh medium in the presence of different concentrations of salicylic acid. The cellular density was measured as $\mathrm{OD}_{600 \mathrm{~nm}}$ after 17 hours (घ) obtaining the salicylate dose-response curves shown in figure. (B) Early growth reactivation elicited by CAMP in chronologically aged yeast cells. A 18 days-aged cyr $1 \Delta p d e 2 \Delta m s n 2 \Delta m s n 4 \Delta$ mutant strain was inoculated into fresh medium supplied $(\bullet)$ or not (घ) with $3 \mathrm{mM}$ cAMP. The $\log _{10}$ of $\mathrm{OD}_{600 \mathrm{~nm}}$ values monitored during mid-log phase were plotted versus time (hours) and fitted with linear regression curves. As the curves were parallel, the time difference at a same mid-log cell density is a convenient estimation of the difference between lag times before growth in the two conditions. CAMP pushed cells to reactivate growth $\sim 1.15$ hours earlier than control cells, as shown graphically.

cyr $1 \Delta$ pde $2 \Delta m s n 2 \Delta m s n 4 \Delta$ mutant challenged with salicylate showed both a defective G1/G0 arrest and small cell size upon starvation (Supplementary Figure S2C and data not shown) and growth recovery inhibition (Figure 3, fully described below). On the other side, aged (18 days) cyr $1 \Delta$ pde $2 \Delta m s n 2 \Delta m s n 4 \Delta$ cells re-inoculated into a fresh medium underwent a faster activation of growth (exit from G0) if supplied with cAMP. The effect was specific as the cyclic nucleotide did not alter the steady state growth rate during the mid-log phase (Figure 2B); this fact also allowed 
us to conveniently quantify the advancement of G0 exit driven with CAMP by measuring the time difference between the curves at a same cell density. In particular, $3 \mathrm{mM}$ cAMP pushed cells to reactivate growth $\sim 1.15$ hours earlier than controls. These experiments fully confirmed the role of CAMP as a limiting signal for exit from $\mathrm{GO}$ and growth reactivation.

We next asked if salicylate and PKAs can exert a truly antagonistic effect on the same cells. Strikingly, when quiescent GG104 cells were treated with $3 \mathrm{mM}$ cAMP they behaved irrespective of the presence of $3 \mathrm{mM}$ salicylate, a concentration that instead per se produced a growth recovery delay of $\sim 2.13$ hours compared to the untreated control. Indeed, the culture experiencing both cAMP and salicylate could start the growth phase $\sim 3.6$ hour earlier than that with only salicylate, behaving just like cells supplied with CAMP alone (Figure $3 \mathrm{~A}$ and Supplementary Figure S6A). So, the stimulatory effect of cAMP appeared to be fully dominant and it was roughly proportional to the concentration of the signal molecule (Supplementary Figure $\mathrm{S} 6 \mathrm{~B})$. The $3 \mathrm{mM}$ exogenous CAMP concentration is likely saturating. As already noted the exponential phase growth rate was largely unaffected by both CAMP and
$3 \mathrm{mM}$ salicylate (Figures 2B, 3A and S6A, B; Doubling Time (DT) was $\sim 2.0$ hours for all cultures).

cAMP cannot suppress the decrease of exponential growth rate due to a high salicylate dosage

When cells were treated with $6 \mathrm{mM}$ salicylate there was also a significant inhibition of the steady-state growth rate during the logarithmic phase; the DT (2.61 hours) was increased by $30-35 \%$ with respect to controls. Although the PKA activation shifted the growth recovery of the culture $\sim 5.22$ hours earlier, the slower proliferation phenotype was not suppressed by CAMP addition (Figure 3B). Noteworthy, the growth curve of cells supplied with $6 \mathrm{mM}$ salicylate+cAMP could not overlap with those of cells challenged with cAMP alone because of the different slope. However, they converged at a cell density similar to that used for the initial cell inoculation (that is $O_{600} \cong 0.005$ ) (Figure 3B inset). So, the delay in cell growth recovery caused by $6 \mathrm{mM}$ salicylate appeared to be completely abolished by CAMP, confirming the results seen with $3 \mathrm{mM}$ salicylate and also the specificity of the CAMP suppression effects.
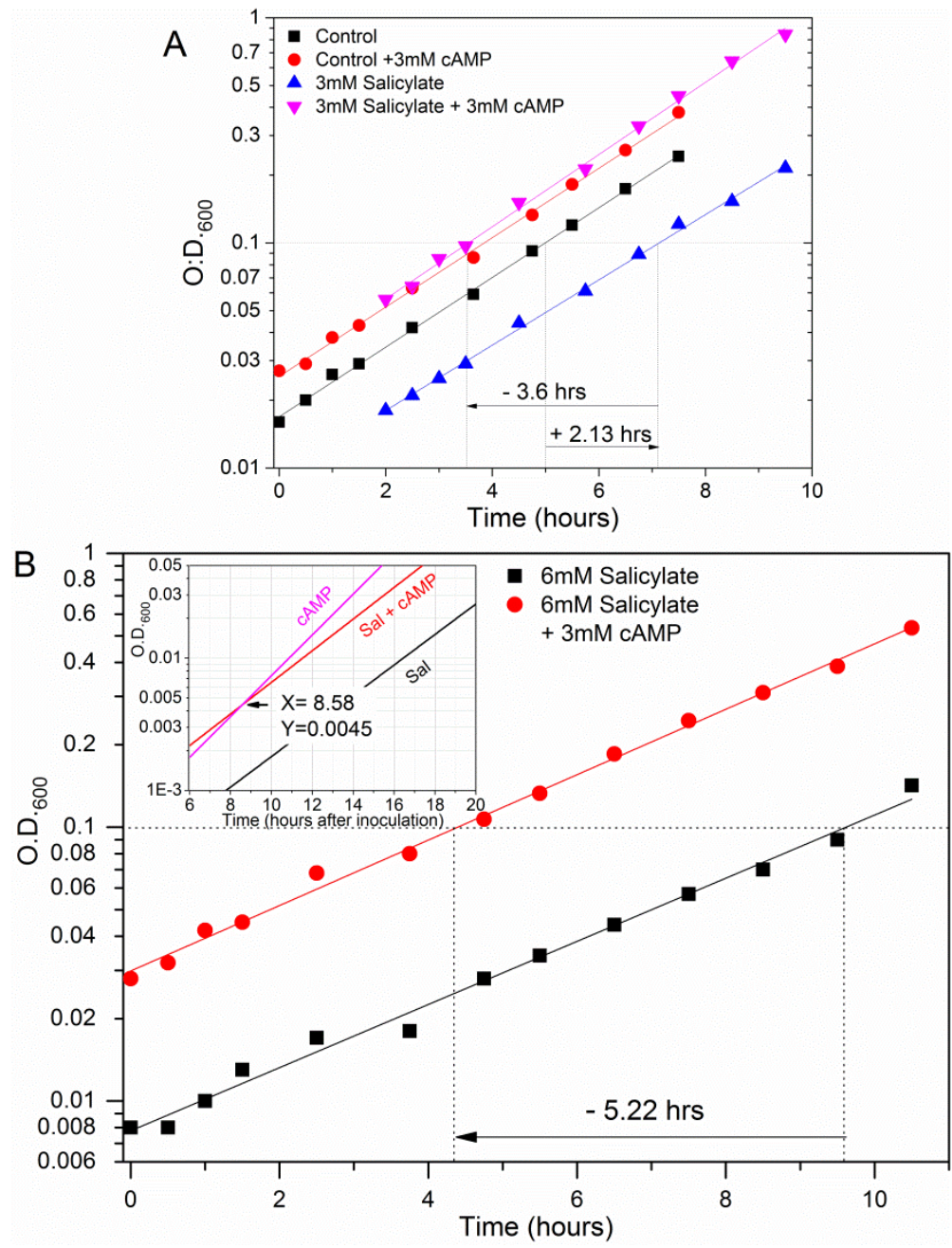

FIGURE 3: Specificity and efficacy of PKA suppressive activity. (A) Dominant cAMP effect in suppressing the SAinduced delay of cell growth recovery. cyr1 1 pde2 $\Delta m s n 2 \Delta m s n 4 \Delta$ long-term quiescent cell populations were supplied $(\bullet)$ or not $(\mathbf{\square})$ with $3 \mathrm{mM}$ cAMP or with $3 \mathrm{mM}$ salicylate plus $(\nabla)$ or minus $(\Delta) 3 \mathrm{mM}$ cAMP when inoculated into fresh medium, monitoring growth by measuring $O D$ at $600 \mathrm{~nm}$. The $\log _{10}$ values of the experimental points were plotted against time (hours) and fitted with linear regression curves. The variations of the time in which growth is reactivated in the different conditions are estimated as explained in the previous figure legend. $3 \mathrm{mM}$ salicylate caused a delay in growth recovery of $\sim 2.13$ hours compared to the untreated control (represented by a right pointing arrow) whereas the culture experiencing both CAMP and salicylate could start the growing phase 3.6 hour earlier than that with the drug alone(left pointing arrow). Noteworthy, its growth curve overlapped that of cells treated only with cAMP. (B) Specificity of cAMP effects for the reactivation but not the rate of cell growth. cyr $1 \Delta$ pde $2 \Delta m s n 2 \Delta m s n 4 \Delta$ mutant cells were treated with 6 $\mathrm{mM}$ salicylate and supplied $(\bullet)$ or not $(\boldsymbol{\square})$ with $3 \mathrm{mM}$ cAMP as described in previous figure. The $\log _{10}$ of $O D_{600 \mathrm{~nm}}$ values taken during the time course experiment were fitted with linear regression curves. At this dosage the drug increased the log-phase generation time from $\sim 2$ to 2.61 hours irrespective of the cAMP presence. However, the addition of cAMP still shifted much earlier, namely $\sim 5.22$ hours (left pointing arrow), the growth recovery of the culture. (The figure is representative of the results of 5 independent experiments). Inset. The regression curves of the above graph are drawn (line colours as in the main graph) together with that of a mutant cell culture supplied with CAMP only (lilac line). The coordinates of the crossing point (arrow) between the two cultures with CAMP are indicated. In particular, the " $6 \mathrm{mM}$ SA+cAMP" and "cAMP only" curves converged at about the cell density of inoculums, namely $\mathrm{OD}_{600} \cong 0.005$, and at a time of $\sim 8.6$ hours (as determined with a graphing software; see Materials and Methods). Note that the moment of inoculation is put here as time zero. 
Table 1. cAMP suppression of salicylate-induced growth reactivation delay.

\begin{tabular}{|c|c|c|c|c|c|c|}
\hline \multicolumn{2}{|c|}{ TREATMENT $^{\mathrm{a}}$} & \multirow{2}{*}{$\begin{array}{c}\begin{array}{r}\text { Doubling } \\
\text { Time (hours) }\end{array} \\
1.94\end{array}$} & \multirow{2}{*}{$\begin{array}{c}\text { Relative } \\
\text { Doubling Time } \\
\text { set as } 1.00\end{array}$} & \multirow{2}{*}{$\begin{array}{c}\begin{array}{r}\text { Time of growh } \\
\text { recovery (hours) }\end{array} \\
9.84\end{array}$} & \multicolumn{2}{|c|}{$\begin{array}{l}\text { Relative time of growth } \\
\text { recovery (hours) }\end{array}$} \\
\hline \multirow{2}{*}{ Control } & --- & & & & 1.18 & $\begin{array}{l}\text { set as } \\
0.00\end{array}$ \\
\hline & $3.0 \mathrm{mM}$ cAMP & 1.95 & 1.01 & 8.66 & $\begin{array}{l}\text { set as } \\
0.00\end{array}$ & -1.18 \\
\hline \multirow{3}{*}{$\begin{array}{l}3 \mathrm{mM} \text { salicy- } \\
\text { late }\end{array}$} & --- & 2.07 & 1.07 & 11.4 & 2.74 & 1.56 \\
\hline & $0.3 \mathrm{mM}$ cAMP & 1.81 & 0.94 & nd & nd & $0.05^{b}$ \\
\hline & $3.0 \mathrm{mM}$ cAMP & 1.87 & 0.96 & 8.7 & 0.04 & -1.14 \\
\hline \multirow{2}{*}{$\begin{array}{l}6 \mathrm{mM} \text { salicy- } \\
\text { late }\end{array}$} & -- & 2.61 & 1.35 & 13.5 & 4.84 & 3.66 \\
\hline & $3 \mathrm{mM}$ cAMP & 2.52 & 1.30 & 8.69 & 0.03 & -1.15 \\
\hline \multirow{2}{*}{$\begin{array}{l}9 \mathrm{mM} \text { salicy- } \\
\text { late }\end{array}$} & --- & 5.05 & 2.60 & 17.9 & 9.24 & 8.06 \\
\hline & $3 \mathrm{mM}$ cAMP & 4.01 & 2.07 & 8.65 & -0.01 & -1.19 \\
\hline \multirow{2}{*}{$\begin{array}{l}12 \mathrm{mM} \text { sa- } \\
\text { licylate }\end{array}$} & -- & no growth & no growth & $>30.5$ & $>21.84$ & $>20.66$ \\
\hline & $3 \mathrm{mM}$ cAMP & 6.42 & 3.31 & 8.80 & 0.14 & -1.04 \\
\hline
\end{tabular}

${ }^{a}$ The calculated values refers to the experiment with GG104 reported in Figure 4 ; ${ }^{b}$ this value refers to the experiment of Supplementary Figure S6B. The salicylate induced delay is calculated by taking either untreated control cells (OMM SA, OmM cAMP) or the cAMP-treated population as a reference.

\section{cAMP signal rescues a strong inhibition of cell growth reactivation and cell lethality caused by salicylate}

A systematic semi-quantitative analysis was performed to compare in a single experiment the growth curves and other parameters of GG104 cells treated with increasing concentrations of salicylate (namely $0,3,6,9$ and $12 \mathrm{mM}$ ) in the presence or not of cAMP. The results generated a quite consistent picture relative to the antagonism between salicylate and the cAMP signal (Figures 4, S6C, S7 and Tables1, 2; described in detail below ).

There was a progressive increase of both the time needed for growth reactivation and the mid-log population DT with the salicylate dosage (Figure 4 upper panel and Table1). Only the first defect was suppressed by cAMP (see below for further details) while the slower exponential growth rate was not corrected by PKA activation, if not very slightly (Figure 4 and Table 1 ) in agreement with the results presented in previous section. In addition, the highest concentration of salicylate $(12 \mathrm{mM})$ completely inhibited yeast cell growth (for at least 33 hours) (Figures 4 upper panel, Supplementary Figures S6C and S7). In this extreme condition the apparent decrease of the $\mathrm{OD}_{600}$ values over time (same figures) prompted us to measure the cell viability within the population (as colony forming unit, CFU). In fact there was a loss of cell viability that became particular- ly dramatic after 20 hours from inoculation and involved virtually all cells after 40 hours (Table 2). Strikingly, this new phenotype was fully rescued by the activation of PKAs with the exogenous cAMP. In addition, these cells kept alive by an elevated CAMP signal also started to grow, although at a slow rate (DT $=6.4$ hours) (Figure 4 lower panel, Tables 1 and 2; Supplementary Figures S6C and S7), reaching remarkable cell densities after 2 days (Supplementary Figure S7, left scale).

It was also evident that all the growth curves of cells stimulated by CAMP strikingly converged at a single point with coordinates Time $(x)=8.66$ hours (cells were inoculates at time 0 ) and $\mathrm{OD}_{600}(\mathrm{y})=0.0046$ (see Materials and Methods) irrespective of the presence of salicylate at any of the used concentrations (so even at $12 \mathrm{mM}$ salicylate) (Figure 4 lower panel; see also Supplementary Figure S6C). The cell density of 0.0046 identified with this larger analysis corresponded again to that of inoculated cells $\left(O D_{600} \cong 0.005\right)$, so confirming and extending what we preliminarily described in the previous section (Fig.3 inset). We concluded that the specific time in which all these growth curves converge can be considered as the common observable time in which cAMP pushed growth reactivation, in a dominant way with respect to the inhibition due to salicylate (Figure 4 and Table 1; Suppl. Fig. S6C). The 


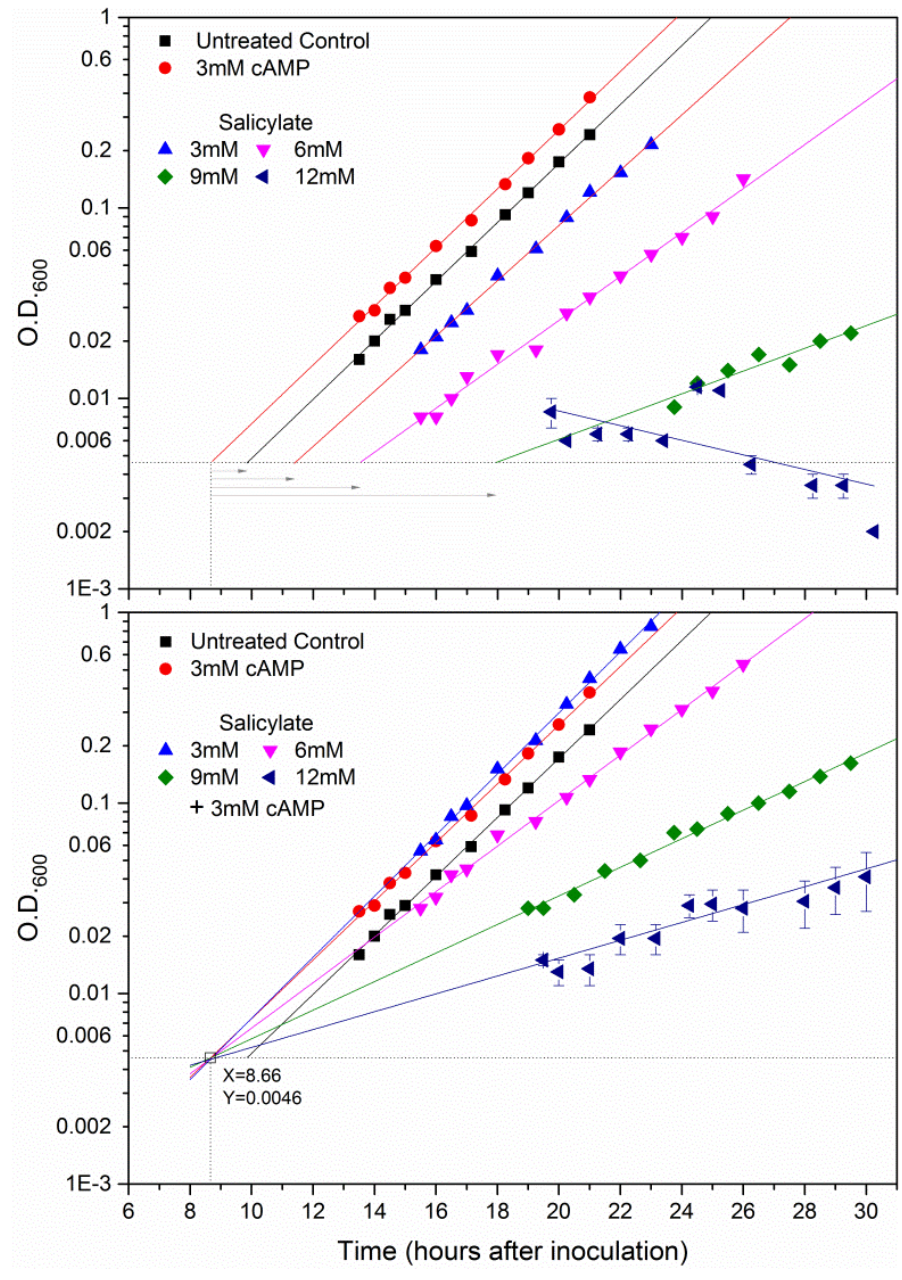

FIGURE 4: Efficient restoration of timely recovery of growth reactivation and rescue of viability of SA-repressed yeast cells by PKA activation. cyr $1 \Delta p d e 2 \Delta m s n 2 \Delta m s n 4 \Delta$ mutant cells were treated with increasing concentrations of salicylate, namely 0 $(\mathbf{\square}, \bullet$; control cells), $3(\Delta), 6(\nabla), 9(\diamond)$ )or $12(\triangleleft) \mathrm{mM} \mathrm{SA}$. The cultures were treated with the increasing concentrations of salicylate in the presence (lower panel) or not (upper panel) of $3 \mathrm{mM}$ cyclic AMP (the same symbol for each salicylate dosage is used in both panels). Control cells without salicylate were also supplied ( $\bullet$ ) or not ( $)$ with $3 \mathrm{mM}$ cAMP (upper and lower panel). Growth was monitored as O.D.600nm. increase and $\log _{10}$ of experimental points were plotted versus time, time zero being when cells were inoculated. The plotted values referring to the conditions of $12 \mathrm{mM}$ salicylate plus or minus CAMP are mean O.D. ${ }_{600 \mathrm{~nm}}$ values $\pm S D$, derived by two time courses followed simultaneously to all the other kinetics. All the experimental points were interpolated by linear regression curves. The values of significant parameters relative to the population growth and viability in these cultures are reported in Tables 1 and 2. There was a progressive inhibition of the exponential growth rate and a systematic increase of the time needed for growth reactivation as a function of salicylate dosage, until proliferation inhibition was a complete at $12 \mathrm{mM}$ salicylate (see also main text). In this severe condition the O.D. $600 \mathrm{~nm}$ decreased along with time, consistent with a dramatic loss of cell viability within the population (Table 2). The activation of PKAs with exogenous cAMP (lower panel) suppressed the loss of viability and the delay of growth reactivation at any salicylate concentration (see also Table 1). This is graphically shown by a single point of convergence (marked by a clear square, $\square$ ) of all the curves with CAMP despite their very different slopes, this point corresponding to the common density of initial inoculums (O.D. ${ }_{600} \cong 0.005$ ) (for more explanations see main text). Its coordinates (dotted lines) were $X=8.66$ hours and $Y=0.0046$ units of O.D. $600 \mathrm{~nm}$ as shown in figure. This unique point was considered also the appropriate reference time (see main text) from which the delays of growth recovery due to salicylate could be calculated in the upper panel as represented by the gray right-pointing arrows of increasing lengths (see also Table 1). growth recovery delay due to each of the different salicylate dosages was calculated with respect to this reference point, namely as the time corresponding an $\mathrm{OD}_{600}=0.0046$ in each growth curve minus 8.66 hours (arrows in upper panel of Fig 4, Table 1; arrows in Suppl. Fig. S6C). As already mentioned, this delay systematically increased with salicylate concentration until there was a complete growth arrest with $12 \mathrm{mM}$ salicylate accompanied by extensive cell death. As expected the untreated control cells also showed a delayed growth reactivation compared to the cAMP supplied cells ( $\sim 1.19$ hours) (Figure 4 and Table 1 ).

Of note, although PKA activation can very efficiently rescue the massive cellular death in these experiments, it could not suppress the G2/M arrest and loss of viability of salicylate treated cells entering the stationary phase, as described in Supplementary Figure S2 (data not shown) consistent with our previous studies [27].

The inhibitory effect of salicylate is not linked to early steps of glucose catabolism

Our experiments were performed in glucose media where SA induced both the inhibition of glucose transport and decreased trehalose 6-phosphate (T6P) and UDP-glucose levels $[13,14]$. Glucose is mostly phosphorylated by hexo- kinases $(H x k 1,2)$ to glucose-6-phosphate, which then fuels glycolysis. Tps1 activity, essential for growth on glucose, converts glucose-6-phosphate and UDP-glucose to T6P which control glucose flux into glycolysis as an allosteric regulator of hexokinases. In order to understand if these early steps of glucose catabolism are involved in SA effects in our system, we repeated the experiments on galactosebased media in which these steps are absent and the highly conserved Leloir pathway is active [28]. In galactose, growth recovery of both wt and cyr1s cells was also strongly inhibited by salicylate (Supplementary Figures S4A, B and Bonferroni statistical analyses in Figure S4C-right panel; Supplementary Figure S5, further described in Discussion). So, the possible inhibition of initial glucose catabolism/signalling by salicylate does not explain the inhibitory phenotypes described here.

\section{DISCUSSION}

Aspirin is one of the most commonly used drugs [1]. Adoption of an Aspirin chemoprevention strategy against CRC (colorectal cancer) and other neoplastic diseases (now based on robust evidence [29]) will greatly benefit from a better understanding of the mechanisms of action of Aspirin [30]. Several cancer prevention properties of Aspirin are 
Table 2. cAMP rescue from yeast cell lethality due to salicylate.

\begin{tabular}{|c|c|c|c|c|c|c|c|c|c|}
\hline \multirow{2}{*}{\multicolumn{2}{|c|}{$\begin{array}{l}\text { Time (hours) }^{a} \\
\text { Yeast Cultures }^{b}\end{array}$}} & \multicolumn{2}{|c|}{0} & \multicolumn{2}{|c|}{21} & \multicolumn{2}{|c|}{26} & \multicolumn{2}{|c|}{40} \\
\hline & & $\# 1$ & $\# 2$ & $\# 1$ & $\# 2$ & $\# 1$ & $\# 2$ & $\# 1$ & $\# 2$ \\
\hline \multicolumn{2}{|c|}{ Treatment } & \multicolumn{8}{|c|}{ Viability (\% CFU ${ }^{c}$ ) } \\
\hline \multirow{2}{*}{$\begin{array}{c}12 \mathrm{mM} \\
\text { salicylate }\end{array}$} & --- & 101.7 & 99.1 & 29.7 & 38.9 & 17.1 & 18.9 & 1.3 & 1.9 \\
\hline & $\begin{array}{l}+3 \mathrm{mM} \\
\text { cAMP }\end{array}$ & 98.9 & 105.9 & 146.8 & 122.4 & 228.5 & 160.7 & 934.5 & 200.2 \\
\hline
\end{tabular}

${ }^{a}$ Time spent in fresh medium after the inoculum of GG104 cells; ${ }^{b}$ Two culture (\#1 and \#2) were monitored in parallel; ${ }^{c}$ Viability was calculated as percent respect to CFU of untreated control cells at the inoculum.

mediated by specific activities of salycilate (SA) affecting several cell processes conserved in eukaryotes, such as glucose metabolism [31, 32] or apoptosis (e.g. see refs $[33,34]$ and citations therein). So, it is not surprising that some of its established targets in mammals, e.g AMPK [31], GCN2 [35], mTORC1 [36] and HMGB1[37], reveal key biological functions from yeast to man.

The budding yeast is a convenient model in which to study how SA can affect processes relevant to neoplastic growth and metabolic disorders [12]. Our study provides a phenotypic platform on which SA-mediated mechanisms, which may be conserved in humans, could be further investigated. We have characterized some SA effects on yeast cell growth and survival, in particular during the crucial transitions from or toward quiescence. Cell quiescence has been the focus of intense research efforts as it can be crucial for maintenance and activation of cancer stem(-like) cells (tumour initiating cells), disseminated tumour cells and dormant micrometastases. Indeed, cancer derived mortality predominantly results from fatal outgrowths derived from these dormant elements even after many years. So, targeting of molecular mechanisms underlying quiescence and growth reactivation may allow sensitization of silent cancer cells to ad hoc therapeutic agents [3840].

In our model system salicylate is able to discriminate between active and quiescent cells. The proliferation of exponential phase cells or cells previously arrested in the stationary phase for a short time were almost completely insensitive to salicylate, given even at doses above the maximum serum concentrations associated to Aspirin therapies (Figures 1, S1 and S3). In contrast quiescent yeast cells were extremely sensitive to SA even at low dosages. Indeed, the exit from a profound quiescent state can be strongly delayed in proportion to the drug concentration and, significantly, cells were already inhibited with dosages overlapping the SA blood levels reached during low-dose
Aspirin cardioprevention therapies [3, 8-10] (Figures 2A and S4).

The same dramatic inhibitory response was observed by treating a strain which cannot produce $3^{\prime}-5^{\prime}$-cyclic-AMP (GG104; significant phenotype: cyr1 $\Delta$ pde2 $\Delta m s n 2 \Delta m s n 4 \Delta$ ) (Figures 3 and 4 upper panel; Supplementary Figure S6), used here because PKAs can be conveniently activated by exogenous CAMP. In this way we demonstrated that the CAMP signal is a limiting factor for taking the cells out of deep quiescence (Figure 2B), in accordance to its known roles in response to glucose [22]. Importantly, this CAMP ability efficiently suppressed the opposite inhibitory action of salicylate delaying or even blocking the growth recovery of G0 cells (Figures 3, 4, S6, S7 and Table 1). We concluded that there is a true antagonistic relationship between the anti-inflammatory and cancer-preventing drug salicylate and key activities of the CAMP signalling pathway in quiescent cells resuming growth.

We tested the suppressive CAMP properties with increasing SA concentrations producing more and more harsh physiological conditions. The duration of the lag time before growth recovery of quiescent GG104 cells progressively increased as a function of SA dosage until, at the highest concentration (12 mM), cell growth was completely inhibited and the cell viability dropped to about $1 \%$ with respect to the untreated control cells. There was also a progressive inhibition of the exponential growth rate starting at $6 \mathrm{mM} \mathrm{SA}$ (Figures 4A and S6, S7; Table1 and 2). Strikingly, PKA activation very efficiently suppressed both the delayed activation of growth at any SA concentrations and the massive cellular death but was completely unable to increase the growth rate (Figures 3, 4, S6, S7; Tables 1 and 2 ). This further supports the existence of specific mechanisms affected by the two antagonistic molecules (Supplementary Figure S8A).

Of note, proper entry into G1/G0 phase was also impaired by salicylate (Supplementary Figure S2) and the cell features observed so far suggest that TOR2 could be a main 
target inhibited by SA [41, 42]. Further analyses on cell cycle and actin cytoskeleton could further support this hypothesis and will be followed by specific molecular analyses.

In order to understand if SA effects involve to some extent the early steps of glucose catabolism in our system, we repeated some key experiments on galactose-based media observing that growth recovery of both wt and cyr $1 \Delta$ cells was strongly inhibited by salicylate (apparently even more than in glucose; see Supplementary Figure S4 and its statistical analyses comparing the response in different media; Supplementary Figure S5). So, the possible impairment of initial glucose catabolism/signalling by salicylate cannot explain the inhibitory phenotypes described here. Interestingly, in the respiro-fermentative regimen driven by galactose the CAMP suppressive activity was reduced in a consistent manner (Supplementary Figure S5), highlighting an important difference in PKA contribution. This is somehow expected as PKA acts positively on cell processes of rapid fermentative growth but negatively on properties associated with slow respirative growth (discussed in [22]). In line with our model, in mammals the CAMP/PKA signalling pathway plays an important role in tumour metabolic (glycolytic) adaptation to oxygen insufficiency [43-46] or to the process of triggering the aerobic glycolysis of cancer associated fibroblasts supplying pyruvate and lactate to tumour cells [47].

Among the possible mechanisms affected by the PKASA interaction we will briefly discuss the involvement of AMPK, based on the literature and our preliminary in silico analyses on the protein structure and sequence (see Materials and Methods). Salicylate is a bona fide activator of AMPK by direct binding to its $\beta 1$ subunit in higher eukaryotes [31]. AMPK is a ubiquitous key energy/metabolic sensor controlling metabolism, cell growth, and survival of eukaryotic cells [48]. In S. cerevisiae, the basic regulation and function of the AMPK $\alpha \beta \gamma$ trimeric structure are conserved (AMPK $\alpha$ is named Snf1). In both yeast and humans, AMPK/Snf1 activation promotes oxidative metabolism used in quiescent cells, rather than the rapid glucose uptake and glycolysis used in many circumstances by proliferating cancer cells and yeast cells cultured in standard $2 \%$ glucose media [49-51].

In yeast antagonistic phenotypic effects [52] and reciprocal inhibition between Snf1 and CAMP-PKA pathways have been described. Snf1 can negatively regulate PKA by Adenylate Cyclase phosphorylation [53] and Snf1-induced phosphorylation of PKA regulatory subunit Bcy1[54]. A (modest) role in Snf1p inhibition is played by PKA phosphorylation of Snf1-activating kinase Sak1 [55]. The PKAdependent dephosphorylating activity of Glc7 PPase on Snf1-Thr210 increases in high glucose [56] inhibiting Snf1/Sip1 localization at the vacuolar membrane [57]. Finally, PKA together with DNA checkpoint kinases (Mec1/ATR and Tel1/ATM) inactives Snf1p by Mms21dependent SUMOylation, as a response to both DNA damage and glucose [58]. Thus, if one assumes that yeast
AMPK is also activated by salicylate the above mechanisms could contribute to some phenotypes shown here.

It has been known that negative relationships between AMPK and PKA pathways also exist in normal and cancer mammalian cells. PKA can directly phosphorylate AMPK at multiple sites $[59,60]$ among which $\alpha 1-S e r 485$ (cf. [61], but the $\alpha 1$-Ser496 is the actual position, hence it will be used here) is a target for AMPK inhibition in primary hepatocytes, producing resistance to metformin [61]. Noteworthy, salicylate can avoid PKA-driven $\alpha 1-S e r 496$ phosphorylation so that CAMP effects are prevented in both cultured hepatocytes and in vivo [61]. AMPKa1-Ser496 is located within regulatory Carboxy Terminal Region (CTD), which shows a modest sequence homology but a striking functional and structural (our in silico analyses; $[62,63]$ ) conservation between yeast and humans. However, although a1-Ser496 $\left({ }^{493} \mathrm{RSGSVSN}^{500}\right)$ belongs to a conserved CTD sub-region it lacks on Snf1, corresponding to a cluster of three negatively charged amino acids $\left({ }^{603}\right.$ SEDEMST $\left.^{609}\right)$, whose significance is unknown.

In contrast, PKA and AMPK associate and PKA phosphorylates the highly conserved (in silico analyses; [62, 63]) AMPK $\alpha 1-S e r 184$ (Snf1-Ser211) $[50,51]$ in primary adipocytes to promote lipolysis, blocking the activating phosphorylation of adjacent conserved key threonine [50,51] of the activation loop ( $\alpha 1-T h r 183 / S n f 1-T h r 210)$ [60]. The PKA-driven AMPK $\alpha 1-S e r 184$ phosphorylation and the complexes between the proteins were found in different human cancer cell lines, suggesting they can have a broader importance [60]. This was strikingly shown by Favre and collaborators that demonstrated how the antitumor effects of AMPK in hepatocellular carcinoma (HCC) cells can be greatly reduced by PKA-driven AMPKa1-Ser184 phosphorylation and the consequent diminution of AMPK activation [64].

Based on our finding and the literature we propose that in S. cerevisiae i) one of the three yeast AMPK $\beta$ subunits could also mediate a direct allosteric Snf1 activation by binding salicylate and ii) at least Snf1-Ser211 might be a key target mediating direct Snf1 repression by PKA. Accordingly, Snf1-Ser211 is phosphorylated in vivo and is located within a predicted PKA phosphorylation site (in silico analyses; [65-68]). The use of SA-treated strains bearing mutated/null versions of Snf1 (and its subunits), cAMPpathway genetic manipulations and direct biochemical analyses have been planned to test these hypotheses. Of note, mammalian AMPK $\alpha$ is functional in otherwise lethal snf1 $1 \Delta$ cells and key elements of its regulatory cascade are also conserved in yeast [69].

AMPK activation is central for cell cycle arrest and apoptosis of glucose-starved HCC characterized by high glycolytic flux [64]. So, it is tempting to speculate that PKA hyperactivation could prevent AMPK/Snf1 induced growth inhibition and even cell lethality in both glucose-starved yeast cells and some cancer cell types with similar mechanisms responding to salicylate.

In general, deregulation of PKA has been related to both initiation and progression of cancer, and has been 
observed in different types of human cancer and cancerassociated stromal cells ([43-47] and citations therein). Salicylate might act as an anti-cancer drug opposing to some activities of the CAMP-PKA signalling pathway. Perhaps more importantly, our work further emphasize that fundamental cell choices are linked to a fragile balance based on metabolic controls, subverted in many ways in tumour cells (Supplementary Figure S8B). This view is strongly strengthened by the fact that salicylate can interacts with some important metabolic hubs conserved in eukaryotes (as indicated by the roles of its established targets in vertebrates; see above), as well as by a recent demonstration that aspirin/salicylate behaves as a bona fide caloric restriction mimetic [70] showing a proautophagic activity dependent on direct SA inhibition of EP300 acetyltransferase activity (with a conserved mechanism) [71]. Intriguingly, EP300 also mediates CAMP driven gene regulation by binding to CREB protein [72]. The observation that starved SA-treated yeast cells have an altered control of last cell divisions not responding to PKA activation (Supplementary Figure S2) supports an even more complex picture of salicylate pleiotropic activities.

As shown in a model summarizing our findings (Supplementary Figure S8), the budding yeast $S$. cerevisiae can provide an unique opportunity to dissect complex conserved mechanisms whose instrumental modification sustain cancer, and to better design their pharmacological control. For instance, it may be desirable to find salicylate derivatives that are more specific for one of its targets or that are no longer antagonized by specific proliferative or anti-apoptotic signals important in certain circumstances (e.g. when they control the metabolism), such as in the case of cAMP. We wonder if the dramatic responses of long-lasting quiescent yeast cells described here could be somehow related to the mechanisms of growth reactivation and survival of dormant cancer cells. This idea, if proven, would greatly increase the importance of our model for identifying new molecular targets/strategies of anti-cancer therapies.

\section{MATERIALS AND METHODS \\ Yeast strains}

The yeast strains used throughout this work (when not otherwise specified) were W303-1A (MATa leu2-3,112 trp1-1 can1100 ura3-1 ade2-1 his3-11,15) [23] and its derivative GG104 (cyr1::kanMX pde2::TRP1 msn2::HIS3 msn4::TRP1 leu2-3,112 trp1-1 can1-100 ura3-1 ade2-1 his3-11,15) [24]. Other strains used were SP1 (MATa his3 leu2 ura3 trp1 ade8 $\mathrm{can}^{\mathrm{r}}$ ) [25] and a fully prototroph version of W303-1A (WP, prepared in our laboratory).

\section{Media and growth conditions}

Yeast cells were cultured at $30^{\circ} \mathrm{C}$ in SD medium (Yeast nitrogen base without amino acids and with ammonium sulphate $6.7 \mathrm{~g} / \mathrm{l}$, Glucose $2 \%$, supplemented with Adenine sulphate $60 \mu \mathrm{g} / \mathrm{ml}$, Uracil $20 \mu \mathrm{g} / \mathrm{ml}$, l-Tryptophan $40 \mu \mathrm{g} / \mathrm{ml}$, I-Histidine hydrochloride $20 \mu \mathrm{g} / \mathrm{ml}$ and/or I-Leucine $60 \mu \mathrm{g} / \mathrm{ml}$ whenever needed by the presence of the corresponding auxotrophies) or the proper selective drop-out CSM (Complete Synthetic Medi- um, supplied by ForMedium, United Kingdom). When required, glucose was substituted with $2 \%$ galactose. All the experiments were performed at $30^{\circ} \mathrm{C}$ in warm room or into an orbital-shaker incubator (only for experiments of Figure 1B). Three independent repeats (defined as measurements taken during different experimental runs) of each experiments were performed (with the exception of the two repetitions of the preliminary analyses shown in Supplementary Figure S5). Repeats of several experiments were performed in triplicate (as specified in figure legends), duplicate (Figs. S1C and S7) or as a single series of measurements (when it was needed to favor the simultaneous analysis of a large number of treatments whose effect had already been explored individually (e.g. the overall experiment of Fig.4; but even in that case, however, the treatments previously showing the most extreme responses were followed in duplicate). All results showed evident consistency and it was always possible to reach the same key conclusions on the biological effects through all similar analyses. Statistics was used for necessarily more quantitative comparisons (Supplementary Figure S4). Aged cell cultures were obtained by incubating cells at $30^{\circ} \mathrm{C}$ in their original medium from 1 day to 3 weeks. An equimolar $0.5 \mathrm{M}$ stock solution of Salicylic acid and Sodium Bicarbonate (Sigma, S5922 and S5771, respectively) was freshly prepared every week. This solution was diluted at the different salicylate concentrations into the growth medium. cAMP (Sigma, A9501) was weighed and added directly to the medium.

\section{Cell parameter measurements}

Growth of cultures as indicated by an increase in cell density

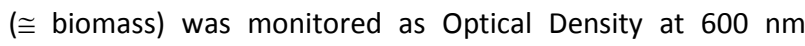
$\left(\mathrm{OD}_{600}\right)$ with a Amersham Pharmacia Ultrospec 1100 Pro Spectrophotometer (Amersham Pharmacia Biotech Ltd, UK). Growth in terms of increase in cell number was followed by using a Coulter Counter model Z2 (Coulter Electronics, Inc.). Cell size analyses were performed using a Coulter Z2 Particle Cell Analyzer (Beckman-Coulter) coupled to the Coulter Counter, obtaining cell volume distributions of yeast populations. The fraction of budded cells was scored by direct microscopic observation on at least 400 cells, fixed in a buffered $(\mathrm{pH} 7.2)$ solution of $2.6 \%$ formaldehyde and mildly sonicated. Cell viability was assessed by cell plating on Yeast-peptone-destrose solid medium (YPDAT; $2 \%$ Agar, $2 \%$ glucose, $1 \%$ yeast extract and $2 \%$ bacto peptone plus Adenine and Tryptophan) through colony forming unit (CFU) counting. Contrast phase light microscopy photographs of yeast cells were obtained with an Olympus $\mathrm{CH} 20$ Microscope (Olympus Corp.).

\section{Flow cytofluorimetric analysis}

A total of about $2 \times 10^{7}$ cells for each sample were collected by centrifugation, fixed in $70 \%$ ethanol, stored at $4^{\circ} \mathrm{C}$ and subsequently processed for flow-cytometry. DNA staining was performed essentially as described previously with some modifications [73]. Cells were washed once with PBS, resuspended in $1 \mathrm{ml}$ of PBS with RNAse $2 \mathrm{mg} / \mathrm{ml}$ and incubated for $4 \mathrm{~h}$ and 30 $\min$ at $37^{\circ} \mathrm{C}$. After incubation, cells were washed once with PBS, resuspended in DNA staining solution (Propidium lodide $0.046 \mathrm{mM}$, Tris $0.05 \mathrm{M}, \mathrm{MgCl}_{2} 15 \mathrm{mM} \mathrm{pH}$ 7.5) and incubated in ice and dark for about $45 \mathrm{~min}$. All the washing and staining steps were performed in $1.5 \mathrm{ml}$ Eppendorf tubes and centrifugations at $16000 \times \mathrm{g}$ for $2 \mathrm{~min}$ at $4^{\circ} \mathrm{C}$. Cell suspensions were transferred in FACS Falcon tubes and sonicated twice for $10 \mathrm{~s}$ 
before analysis. Analyses were performed using a CYTOFLEX $S$ Beckman Coulter equipped with a 488-nm laser emission. Plot generation was performed with CytExpert 2.0 software (Beckman Coulter).

\section{Graphics and statistics}

All graphics processing and calculations as well as growth curve fittings and statistics were performed using OriginPro9.1 (64bit), a data analysis and graphing software (OriginLab Corporation, One Roundhouse Plaza, Suite 303, Northampton, MA 01060, USA).

\section{In silico analyses}

The 3D structure and sequence of AMPK $\alpha$ (in particular its CTD) were compared between yeast and humans protein version using PyMOL [62] and PROMALS3D [63] programs. The conservation of Snf1-Ser211 was confirmed by comparing the sequence of AMPK $\alpha$ among a large number of species.

The putative PKA phosphorylation sites were searched with pkaPS on line program $[65,66]$. The phosphorylated residues of AMPK and Snf1 (with the associated consensus sequence for different protein kinases) both in vivo and in vitro were scored using the PhosphoSitePlus ${ }^{\circledR}$ (PSP) and/or PhosphoGRID databases $[67,68]$.

\section{ACKNOWLEDGMENTS}

We are particularly grateful to Dr. Linda Cairns (Scientific Editor, ecancermedicalscience; European Institute of On-

\section{REFERENCES}

1. Vane JR, and Botting RM (2003). The mechanism of action of aspirin. Thromb Res 110(5-6): 255-258. 14592543. doi:10.1016/S00493848(03)00379-7

2. Vlot AC, Dempsey DA, and Klessig DF (2009). Salicylic Acid, a multifaceted hormone to combat disease. Annu Rev Phytopathol 47: 177206. doi: 10.1146/annurev.phyto.050908.135202

3. Jeffreys D (2004). Aspirin: The Remarkable Story of a Wonder Drug. Bloomsbury Publishing, New York.

4. Wang J, Zhang C-J, Zhang J, He Y, Lee YM, Chen S, Lim TK, Ng S, Shen $\mathrm{H}-\mathrm{M}$, and Lin Q (2015). Mapping sites of aspirin-induced acetylations in live cells by quantitative acid-cleavable activity-based protein profiling (QA-ABPP). Sci Rep 5: 7896. doi: 10.1038/srep07896

5. Serhan CN, Chiang N, and Dalli J (2015). The resolution code of acute inflammation: Novel pro-resolving lipid mediators in resolution. Semin Immunol 27(3): 200-215. doi: 10.1016/j.smim.2015.03.004

6. Levy G (1978). Clinical pharmacokinetics of aspirin. Pediatrics 62(5 Pt 2 Suppl): 867-872. PMID: 724339

7. Williams FM (1985). Clinical significance of esterases in man. Clin Pharmacokinet 10(5): 392-403. doi: 10.2165/00003088-19851005000002

8. Needs CJ, and Brooks PM (1985). Clinical pharmacokinetics of the salicylates. Clin Pharmacokinet 10(2): 164-177. doi:

10.2165/00003088-198510020-00004

9. Higgs GA, Salmon JA, Henderson B, and Vane JR (1987). Pharmacokinetics of aspirin and salicylate in relation to inhibition of arachidonate cyclooxygenase and antiinflammatory activity. Proc Natl Acad Sci USA 84(5): 1417-1420. doi: 10.1073/pnas.84.5.1417

10. Lawrence JR, Peter R, Baxter GJ, Robson J, Graham AB, and Paterson JR (2003). Urinary excretion of salicyluric and salicylic acids by cology) for her professional English revision of the manuscript.

This work was supported by Scientific Research DOR funds (2016-2017) from the University of Padua to MDB and FAR 2016 grant from the University of Milano-Bicocca to EM.

\section{SUPPLEMENTAL MATERIAL}

All supplemental data for this article are available online at www.microbialcell.com.

\section{CONFLICT OF INTEREST}

The authors declare no conflict of interest.

\section{COPYRIGHT}

(C) 2018 Baroni et al. This is an open-access article released under the terms of the Creative Commons Attribution (CC BY) license, which allows the unrestricted use, distribution, and reproduction in any medium, provided the original author and source are acknowledged.

Please cite this article as: Maurizio D. Baroni, Sonia Colombo and Enzo Martegani (2018). Antagonism between Salicylate and the cAMP signal controls yeast cell survival and growth recovery from quiescence. Microbial Cell 5(7): 344-356. doi: 10.15698/mic2018.07.640 non-vegetarians, vegetarians, and patients taking low dose aspirin. J Clin Pathol 56(9): 651-653. doi: 10.1136/jcp.56.9.651

11. Umar A, Steele VE, Menter DG, and Hawk ET (2016). Mechanisms of nonsteroidal anti-inflammatory drugs in cancer prevention. Semin Oncol 43(1): 65-77. doi: 10.1053/j.seminoncol.2015.09.010

12. Farrugia G, and Balzan R (2013). The proapoptotic effect of traditional and novel nonsteroidal anti-inflammatory drugs in mammalian and yeast cells. Oxid Med Cell Longev 2013: 504230. doi: $10.1155 / 2013 / 504230$

13. Scharff TG, Badr MZ, and Doyle RJ (1982). The nature of salicylate inhibition of sugar transport in yeast. Fundam Appl Toxicol 2(4): 168172. doi: 10.1016/S0272-0590(82)80041-9

14. Moses V, and Smith MJ (1960). Uncoupling reagents and metabolism. 2. Effects of 2:4-dinitrophenol and salicylate on glucose metabolism in baker's yeast. Biochem J 76: 585-594. doi: 10.1042/bj0760585

15. Farrugia G, Bannister WH, Vassallo N, and Balzan R (2013). Aspirininduced apoptosis of yeast cells is associated with mitochondrial superoxide radical accumulation and $\mathrm{NAD}(\mathrm{P}) \mathrm{H}$ oxidation. FEMS Yeast Res 13(8): 755-768. doi: 10.1111/1567-1364.12075

16. Yiannakopoulou EC, and Tiligada E (2009). Protective effect of salicylates against hydrogen peroxide stress in yeast. J Appl Microbiol 106(3): 903-908. doi: 10.1111/j.1365-2672.2008.04061.x

17. Sapienza K, Bannister W, and Balzan R (2008). Mitochondrial involvement in aspirin-induced apoptosis in yeast. Microbiology 154(Pt 9): 2740-2747. doi: 10.1099/mic.0.2008/017228-0

18. Balzan R, Sapienza K, Galea DR, Vassallo N, Frey H, and Bannister $\mathrm{WH}$ (2004). Aspirin commits yeast cells to apoptosis depending on carbon source. Microbiology 150(Pt 1): 109-115. doi: 10.1099/mic.0.26578-0 
19. Giardina C, and Lis JT (1995). Sodium salicylate and yeast heat shock gene transcription. J Biol Chem 270(18): 10369-10372. doi: 10.1074/jbc.270.18.10369

20. van Leeuwen JS, Unlü B, Vermeulen NPE, and Vos JC (2012). Differential involvement of mitochondrial dysfunction, cytochrome P450 activity, and active transport in the toxicity of structurally related NSAIDs. Toxicol In Vitro 26(2): 197-205. doi:

10.1016/j.tiv.2011.11.013

21. He C, Tsuchiyama SK, Nguyen QT, Plyusnina EN, Terrill SR, Sahibzada S, Patel B, Faulkner AR, Shaposhnikov MV, Tian R, Tsuchiya M, Kaeberlein M, Moskalev AA, Kennedy BK, and Polymenis M (2014). Enhanced longevity by ibuprofen, conserved in multiple species, occurs in yeast through inhibition of tryptophan import. PLoS Genet 10(12): e1004860. doi: 10.1371/journal.pgen.1004860

22. Conrad M, Schothorst J, Kankipati HN, Van Zeebroeck G, RubioTexeira M, and Thevelein JM (2014). Nutrient sensing and signaling in the yeast Saccharomyces cerevisiae. FEMS Microbiol Rev 38(2): 254299. doi: 10.1111/1574-6976.12065

23. Longo VD, Shadel GS, Kaeberlein M, and Kennedy B (2012). Replicative and chronological aging in Saccharomyces cerevisiae. Cell Metab 16(1): 18-31. doi: 10.1016/j.cmet.2012.06.002

24. Roosen J, Engelen K, Marchal K, Mathys J, Griffioen G, Cameroni E, Thevelein JM, De Virgilio C, De Moor B, and Winderickx J (2005). PKA and Sch9 control a molecular switch important for the proper adaptation to nutrient availability. Mol Microbiol 55(3): 862-880. doi: 10.1111/j.1365-2958.2004.04429.x

25. Baroni MD, Monti P, Marconi G, and Alberghina L (1992). cAMPmediated increase in the critical cell size required for the $G 1$ to $S$ transition in Saccharomyces cerevisiae. Exp Cell Res.201(2): 299-306. PMID: 1322313

26. Amigoni L, Colombo S, Belotti F, Alberghina L, and Martegani E (2015). The transcription factor Swi4 is target for PKA regulation of cell size at the $\mathrm{G} 1$ to $\mathrm{S}$ transition in Saccharomyces cerevisiae. Cell Cycle 14(15): 2429-2438. doi: 10.1080/15384101.2015.1055997

27. Anghileri $P$, Branduardi $P$, Sternieri $F$, Monti $P$, Visintin $R$, Bevilacqua A, Alberghina L, Martegani E, and Baroni MD (1999). Chromosome separation and exit from mitosis in budding yeast: dependence on growth revealed by CAMP-mediated inhibition. Exp Cell Res 250(2): 510-523. doi: 10.1006/excr.1999.4531

28. Kew OM, and Douglas HC (1976). Genetic co-regulation of galactose and melibiose utilization in Saccharomyces. J Bacteriol 125(1) 33-41. PMID: 1245460

29. Thun MJ, Jacobs EJ, and Patrono C (2012). The role of aspirin in cancer prevention. Nat Rev Clin Oncol 9(5): 259-267. doi:

10.1038/nrclinonc.2011.199

30. Drew DA, Cao Y, and Chan AT (2016). Aspirin and colorectal cancer: the promise of precision chemoprevention. Nat Rev Cancer 16(3): 173-186. doi: 10.1038/nrc.2016.4

31. Hawley SA, Fullerton MD, Ross FA, Schertzer JD, Chevtzoff C, Walker KJ, Peggie MW, Zibrova D, Green KA, Mustard KJ, Kemp BE, Sakamoto K, Steinberg GR, and Hardie DG (2012). The ancient drug salicylate directly activates AMP-activated protein kinase. Science 336(6083): 918-922. doi: 10.1126/science.1215327

32. Smith BK, Ford RJ, Desjardins EM, Green AE, Hughes MC, Houde VP, Day EA, Marcinko K, Crane JD, Mottillo EP, Perry CGR, Kemp BE, Tarnopolsky MA, and Steinberg GR (2016). Salsalate (Salicylate) Uncouples Mitochondria, Improves Glucose Homeostasis, and Reduces Liver Lipids Independent of AMPK- $\beta 1$. Diabetes 65(11): 3352-3361. doi: $10.2337 / \mathrm{db} 16-0564$

33. Liu Y, Wang Y, Hu Y, Ge S, Li K, Wang S, and Li L (2017). The apoptotic inducible effects of salicylic acid on hepatoma cell line: relation- ship with nitric oxide signaling. J Cell Commun Signal 11(3): 245-253. doi: 10.1007/s12079-017-0380-z

34. Lai M-Y, Huang J-A, Liang Z-H, Jiang H-X, and Tang G-D (2008). Mechanisms underlying aspirin-mediated growth inhibition and apoptosis induction of cyclooxygenase- 2 negative colon cancer cell line SW480. World J Gastroenterol 14(26): 4227-4233. doi: 10.3748/wjg.14.4227

35. Gentz SHL, Bertollo CM, Souza-Fagundes EM, and da Silva AM (2013). Implication of elF2 $\alpha$ kinase GCN2 in induction of apoptosis and endoplasmic reticulum stress-responsive genes by sodium salicylate. J Pharm Pharmacol 65(3): 430-440. doi: 10.1111/jphp.12002

36. Henry WS, Laszewski T, Tsang T, Beca F, Beck AH, McAllister SS, and Toker A (2017). Aspirin Suppresses Growth in PI3K-Mutant Breast Cancer by Activating AMPK and Inhibiting mTORC1 Signaling. Cancer Res 77(3): 790-801. doi: 10.1158/0008-5472.CAN-16-2400

37. Yang $H$, Pellegrini L, Napolitano A, Giorgi C, Jube S, Preti A, Jennings CJ, De Marchis F, Flores EG, Larson D, Pagano I, Tanji M, Powers A, Kanodia S, Gaudino G, Pastorino S, Pass HI, Pinton P, Bianchi ME, and Carbone $M$ (2015). Aspirin delays mesothelioma growth by inhibiting HMGB1-mediated tumor progression. Cell Death Dis 6: e1786. doi: 10.1038/cddis.2015.153

38. Peitzsch C, Tyutyunnykova A, Pantel K, and Dubrovska A (2017). Cancer stem cells: The root of tumor recurrence and metastases. Semin Cancer Biol 44: 10-24. doi: 10.1016/j.semcancer.2017.02.011

39. Sosa MS, Bragado P, and Aguirre-Ghiso JA (2014). Mechanisms of disseminated cancer cell dormancy: an awakening field. Nat Rev Cancer 14(9): 611-622. doi: 10.1038/nrc3793

40. Chen W, Dong J, Haiech J, Kilhoffer M-C, and Zeniou M (2016). Cancer Stem Cell Quiescence and Plasticity as Major Challenges in Cancer Therapy. Stem Cells Int 2016: 1740936. doi: 10.1155/2016/1740936

41. Schmidt A, Kunz J, and Hall MN (1996). TOR2 is required for organization of the actin cytoskeleton in yeast. Proc Natl Acad Sci USA 93(24): 13780-13785. doi: 10.1073/pnas.93.24.13780

42. Gaubitz C, Oliveira TM, Prouteau M, Leitner A, Karuppasamy M, Konstantinidou G, Rispal D, Eltschinger S, Robinson GC, Thore S, Aebersold R, Schaffitzel C, and Loewith R (2015). Molecular Basis of the Rapamycin Insensitivity of Target Of Rapamycin Complex 2. Mol Cell 58(6): 977-988. doi: 10.1016/j.molcel.2015.04.031

43. Simko V, Iuliano F, Sevcikova A, Labudova M, Barathova M, Radvak $P$, Pastorekova S, Pastorek J, and Csaderova $L$ (2017). Hypoxia induces cancer-associated cAMP/PKA signalling through HIF-mediated transcriptional control of adenylyl cyclases VI and VII. Sci Rep 7(1): 10121. doi: 10.1038/s41598-017-09549-8

44. Shaikh D, Zhou Q, Chen T, Ibe JCF, Raj JU, and Zhou G (2012). cAMP-dependent protein kinase is essential for hypoxia-mediated epithelial-mesenchymal transition, migration, and invasion in lung cancer cells. Cell Signal 24(12): 2396-2406. doi: 10.1016/j.cellsig.2012.08.007

45. Finger EC, Castellini L, Rankin EB, Vilalta M, Krieg AJ, Jiang D, Banh $A$, Zundel W, Powell MB, and Giaccia AJ (2015). Hypoxic induction of AKAP12 variant 2 shifts PKA-mediated protein phosphorylation to enhance migration and metastasis of melanoma cells. Proc Natl Acad Sci USA 112(14): 4441-4446. doi: 10.1073/pnas.1418164112

46. Bullen JW, Tchernyshyov I, Holewinski RJ, DeVine L, Wu F, Venkatraman V, Kass DL, Cole RN, Van Eyk J, and Semenza GL (2016). Protein kinase A-dependent phosphorylation stimulates the transcriptional activity of hypoxia-inducible factor 1 . Sci Signal 9(430): ra56. doi: 10.1126/scisignal.aaf0583

47. Yu T, Yang G, Hou Y, Tang X, Wu C, Wu X-A, Guo L, Zhu Q, Luo H, Du Y-E, Wen S, Xu L, Yin J, Tu G, and Liu M (2017). Cytoplasmic GPER 
translocation in cancer-associated fibroblasts mediates CAMP/PKA/CREB/glycolytic axis to confer tumor cells with multidrug resistance. Oncogene 36(15): 2131-2145. doi: 10.1038/onc.2016.370

48. Villanueva-Paz M, Cotán D, Garrido-Maraver J, Oropesa-Ávila M, de la Mata M, Delgado-Pavón A, de Lavera I, Alcocer-Gómez E, Álvarez-Córdoba $M$, and Sánchez-Alcázar JA (2016). AMPK Regulation of Cell Growth, Apoptosis, Autophagy, and Bioenergetics. EXS. 107: 4571. doi: 10.1007/978-3-319-43589-3_21

49. Angin Y, Beauloye C, Horman S, and Bertrand L (2016). Regulation of Carbohydrate Metabolism, Lipid Metabolism, and Protein Metabolism by AMPK. EXS.107: 23-43. doi: 10.1007/978-3-319-43589-3_2

50. Kurumbail RG, and Calabrese MF (2016). Structure and Regulation of AMPK. EXS 107: 3-22. doi: 10.1007/978-3-319-43589-3_1

51. Sanz P, Viana R, and Garcia-Gimeno MA (2016). AMPK in Yeast: The SNF1 (Sucrose Non-fermenting 1) Protein Kinase Complex. EXS 107: 353-374. doi: 10.1007/978-3-319-43589-3_14

52. Thompson-Jaeger S, François J, Gaughran JP, and Tatchell K (1991). Deletion of SNF1 affects the nutrient response of yeast and resembles mutations which activate the adenylate cyclase pathway. Genetics 129(3): 697-706. PMID: 1752415

53. Nicastro R, Tripodi F, Gaggini M, Castoldi A, Reghellin V, Nonnis S, Tedeschi G, and Coccetti P (2015). Snf1 Phosphorylates Adenylate Cyclase and Negatively Regulates Protein Kinase A-dependent Transcription in Saccharomyces cerevisiae. J Biol Chem 290(41): 2471524726. doi: 10.1074/jbc.M115.658005

54. Braun KA, Vaga S, Dombek KM, Fang F, Palmisano S, Aebersold R, and Young ET (2014). Phosphoproteomic analysis identifies proteins involved in transcription-coupled mRNA decay as targets of Snf1 signaling. Sci Signal 7(333): ra64. doi: 10.1126/scisignal.2005000

55. Barrett L, Orlova M, Maziarz M, and Kuchin S (2012). Protein kinase $A$ contributes to the negative control of Snf1 protein kinase in Saccharomyces cerevisiae. Eukaryotic Cell 11(2): 119-128. doi: 10.1128/EC.05061-11

56. Castermans D, Somers I, Kriel J, Louwet W, Wera S, Versele M, Janssens V, and Thevelein JM (2012). Glucose-induced posttranslational activation of protein phosphatases PP2A and PP1 in yeast. Cell Res 22(6): 1058-1077. doi: 10.1038/cr.2012.20

57. Hedbacker K, Townley R, and Carlson M (2004). Cyclic AMPdependent protein kinase regulates the subcellular localization of Snf1-Sip1 protein kinase. Mol Cell Biol 24(5): 1836-1843. doi: 10.1128/MCB.24.5.1836-1843.2004

58. Simpson-Lavy KJ, Bronstein A, Kupiec M, and Johnston M (2015). Cross-Talk between Carbon Metabolism and the DNA Damage Response in S. cerevisiae. Cell Rep 12(11): 1865-1875. doi: 10.1016/j.celrep.2015.08.025

59. Hurley RL, Barré LK, Wood SD, Anderson KA, Kemp BE, Means AR, and Witters LA (2006). Regulation of AMP-activated protein kinase by multisite phosphorylation in response to agents that elevate cellular cAMP. J Biol Chem 281(48): 36662-36672. doi: 10.1074/jbc.M606676200

60. Djouder N, Tuerk RD, Suter M, Salvioni P, Thali RF, Scholz R, Vaahtomeri K, Auchli Y, Rechsteiner H, Brunisholz RA, Viollet B, Mäke- lä TP, Wallimann T, Neumann D, and Krek W (2010). PKA phosphorylates and inactivates AMPKalpha to promote efficient lipolysis. EMBO J 29(2): 469-481. doi: 10.1038/emboj.2009.339

61. He L, Chang E, Peng J, An H, McMillin SM, Radovick S, Stratakis CA, and Wondisford FE (2016). Activation of the CAMP-PKA pathway Antagonizes Metformin Suppression of Hepatic Glucose Production. J Biol Chem 291(20): 10562-10570. doi: 10.1074/jbc.M116.719666

62. PyMOL - A molecular visualization system on an open source foundation, maintained and distributed by Schrödinger. Available at: https://www.pymol.org/

63. PROMALS3D - Multiple sequence and structure alignment server. Available at: http://prodata.swmed.edu/promals3d/promals3d.php

64. Ferretti AC, Tonucci FM, Hidalgo F, Almada E, Larocca MC, and Favre $C$ (2016). AMPK and PKA interaction in the regulation of survival of liver cancer cells subjected to glucose starvation. Oncotarget $7(14)$ : 17815-17828. doi: 10.18632/oncotarget.7404

65. IMP Bioinformatics Group: pkaPS - Prediction of protein kinase A phosphorylation sites using the simplified kinase binding model. Available at: http://mendel.imp.ac.at/pkaPS/

66. Neuberger G, Schneider G, and Eisenhaber F (2007). pkaPS: prediction of protein kinase $A$ phosphorylation sites with the simplified kinase-substrate binding model. Biol Direct 2: 1. doi: 10.1186/17456150-2-1

67. PhosphoSitePlus ${ }^{\circledR}$ (PSP) - An online systems biology resource providing comprehensive information and tools for the study of protein post-translational modifications. Available at:

http://www.phosphosite.org/

68. PhosphoGRID - An online database of experimentally verified in vivo protein phosphorylation sites in the model eukaryotic organism Saccharomyces cerevisiae. Available at: https://phosphogrid.org/

69. Hedbacker K, and Carlson M (2008). SNF1/AMPK pathways in yeast. Front Biosci 13: 2408-2420. doi: 10.2741/2854

70. Madeo F, Pietrocola F, Eisenberg T, and Kroemer G (2014). Caloric restriction mimetics: towards a molecular definition. Nat Rev Drug Discov 13(10): 727-740. doi: 10.1038/nrd4391

71. Pietrocola F, Castoldi F, Markaki M, Lachkar S, Chen G, Enot DP, Durand S, Bossut N, Tong M, Malik SA, Loos F, Dupont N, Mariño G, Abdelkader N, Madeo F, Maiuri MC, Kroemer R, Codogno P, Sadoshima J, Tavernarakis N, and Kroemer G (2018). Aspirin Recapitulates Features of Caloric Restriction. Cell Rep 22(9): 2395-2407. doi: 10.1016/j.celrep.2018.02.024

72. Wang F, Marshall CB, and Ikura M (2013). Transcriptional/epigenetic regulator $\mathrm{CBP} / \mathrm{p} 300$ in tumorigenesis: structural and functional versatility in target recognition. Cell Mol Life Sci 70(21): 3989-4008. doi: 10.1007/s00018-012-1254-4

73. Belotti F, Tisi R, and Martegani E (2006). The $\mathrm{N}$-terminal region of the Saccharomyces cerevisiae RasGEF Cdc25 is required for nutrientdependent cell-size regulation. Microbiology 152(Pt 4): 1231-1242. doi: 10.1099/mic.0.28683-0 